\begin{tabular}{|c|c|c|c|}
\hline \multirow{3}{*}{$\begin{array}{r}\text { Case Reports in } \\
\text { Gastroenterology }\end{array}$} & \multicolumn{2}{|c|}{ Case Rep Gastroenterol 2020;14:98-102 } & \multirow[b]{2}{*}{$\begin{array}{l}\text { Karger } \\
\text { Open'access }\end{array}$} \\
\hline & $\begin{array}{l}\text { DOI: } 10.1159 / 000506185 \\
\text { Published online: February 21, } 2020\end{array}$ & $\begin{array}{l}\text { (c) } 2020 \text { The Author(s) } \\
\text { Published by S. Karger AG, Basel } \\
\text { www.karger.com/crg }\end{array}$ & \\
\hline & $\begin{array}{l}\text { This article is licensed under the } \\
\text { International License (CC BY-NC) } \\
\text { Usage and distribution for commerci }\end{array}$ & $\begin{array}{l}\text { nons Attribution-NonCommercial } 4.0 \\
\text { ger.com/Services/OpenAccessLicense). } \\
\text { uires written permission. }\end{array}$ & \\
\hline
\end{tabular}

\title{
Multidisciplinary Treatment of Advanced Hepatocellular Carcinoma
}

\author{
Zhe Yang $^{\mathrm{a}}$ Bulat Abdrakhimov ${ }^{\mathrm{b}}$ Shuo Wang ${ }^{\mathrm{a}}$ Qin-Fen Xie \\ Shu-Sen Zheng ${ }^{a}$ \\ aDepartment of Hepatobiliary and Pancreatic Surgery, Shulan (Hangzhou) Hospital, \\ Hangzhou, China; 'bhejiang University School of Medicine, Hangzhou, China
}

\section{Keywords}

Hepatocellular carcinoma $\cdot$ Multidisciplinary treatment $\cdot$ Case report

\begin{abstract}
Current strategy for treatment of hepatocellular carcinoma (HCC) based on Barcelona-Clinic Liver Cancer (BCLC) criteria dictates that patients with advanced-stage $\mathrm{HCC}$ are to only receive treatment with tyrosine kinase inhibitors. However, they prolong overall survival just by slightly more than 6 months. In this article, we present a patient with HCC diagnosed at an advanced stage who received multidisciplinary treatment consisting of transarterial chemoembolization, hepatic resection, pulmonary resection, radiofrequency ablation, tyrosine kinase inhibitors, and radiotherapy, and has survived for more than 2 years since diagnosis and counting.
\end{abstract}

(C) 2020 The Author(s)

Published by S. Karger AG, Basel

\section{Introduction}

Hepatocellular carcinoma (HCC) is the 4th leading cause of cancer death in the world, largely owing this rank to its high incidence in Asian countries such as China [1,2]. HCC is often associated with chronic diseases, most notably hepatitis B and C virus infections [3]. Improvement of diagnostic modalities and advances in treatment for HCC led to a greatly increased survival rate in the past decades [4], but it remains rather low in patients who were diagnosed at later stages, one of the reasons being the limitations of the treatment strategies. 
Yang et al.: Multidisciplinary Treatment of Advanced Hepatocellular Carcinoma

\section{Case Presentation}

A 46-year-old male came to our hospital with abdominal pain on exertion for 1 month. There were no other symptoms present. Abdominal CT scan showed cirrhotic liver, splenomegaly, and multiple lesions (the biggest $-15 \times 13 \mathrm{~cm}$ ) in segments V and VI (Fig. 1a); no metastases were found on chest/abdominal-pelvic CT. Laboratory data showed that anti-HBc, HBeAg, HBsAg were positive, AFP was elevated $(2,025 \mathrm{ng} / \mathrm{mL})$, and other tumor markers (CEA, CA125, CA19-9) and bilirubin levels were within normal ranges. His past history and family history were unremarkable. In spite of seemingly big tumor burden, the patient was classified as Child-Pugh A with ECOG-PS 0, placing him in the advanced-stage group (Barcelona-Clinic Liver Cancer [BCLC] C). Nonetheless, because of preserved liver function and good performance status, a decision to perform hepatectomy with application of TACE was made by an institutional multidisciplinary board.

During the hospital stay, the patient had tumor rupture that was treated with bland transarterial embolization (gelatin sponge administration) (Fig. 1b). He was also prescribed entecavir because of HBV infection. The patient underwent partial hepatectomy 2 months after transarterial embolization. In addition, due to tumor invasion to surrounding organs, enterotomy of approximately $10 \mathrm{~cm}$ was made in the colon, and cholecystectomy was performed (Fig. 1c). The pathology result showed poorly to moderately differentiated HCC without microvascular invasion; no signs of metastases were found in harvested lymph nodes. The patient then received 2 cycles of transarterial chemoembolization (TACE) consisting of oxaliplatin and epirubicin-lipiodol emulsion, 2 and 5 months after hepatectomy.

Shortly after the 3rd TACE, chest CT revealed 2 nodules in the left lung (Fig. 2a, b), which were subsequently removed via thoracoscopic wedge resection. The pathology confirmed those nodules to be HCC metastases. After 1 month, blood test showed elevated AFP level $(249.6 \mathrm{ng} / \mathrm{mL})$, and a small mass (diameter $-1 \mathrm{~cm}$ ) was discovered near the caudate lobe of liver and resected using a laparoscopic approach. TACE (oxaliplatin and epirubicin-lipiodol emulsion) was performed 2 weeks after that. Three months later, chest CT showed a solitary nodule in the right lung (Fig. 2c) that was treated with radiofrequency ablation (Fig. 2d). After 2 months, as AFP and PIVKA-II levels were elevated $(5,763.2 \mathrm{ng} / \mathrm{mL}$ and $62 \mathrm{mAu} / \mathrm{mL}$, respectively), ${ }^{18} \mathrm{~F}$ FDG-PET/CT was performed. It revealed metastases in the left hilar lymph nodes $\left(S_{\text {Uax }}-7.25\right.$, diameter $-25 \mathrm{~mm}$; Fig. 3a, b). The patient had begun receiving sorafenib after discharge, but it was changed to regorafenib 2 months later due to tumor progression; he had also soon received radiotherapy (5,000 cGy/25f, $200 \mathrm{cGy} / \mathrm{f}, 5 \mathrm{f} / \mathrm{w})$. Two months after the end of radiotherapy, CT scan showed no signs of metastases (Fig. 3c), and both AFP and PIVKA-II levels normalized (Fig. 4). The patient reported his condition as fine and did not complain of any discomfort.

\section{Discussion}

While BCLC treatment strategy states tyrosine kinase inhibitors (sorafenib, regorafenib, and lenvatinib) as sole treatment for advanced-stage HCC [5], the incorporation of different treatment modalities advances. HCC can be treated with multimodal approach with the application of treatments ranging from surgery to radiation oncology in order to increase survival rate.

Hepatectomy is a primary treatment option in case of resectable metastatic tumor, though associated with high risk of postoperative liver failure and poor clinical outcome because of 
usually preexisting chronic liver disease [6]. However, surgery alone is not enough for treatment of advanced-stage HCC and must be combined with other treatments. According to a recent meta-analysis, postoperative TACE for advanced HCC was shown to increase overall survival rate [7]. Furthermore, another study found that male patients with cirrhosis, age $<60$ years, tumor $>10 \mathrm{~cm}$, and resection margin $<2 \mathrm{~cm}$ may derive a greater survival benefit from adjuvant TACE [8].

Tyrosine kinase inhibitors are crucial in systemic treatment of HCC as they hinder tumor progression and improve overall survival rate [9]. Some studies have concluded that sorafenib also may enhance tumor sensitivity to radiotherapy [10]. Patients with metastases from HCC can benefit from radiotherapy in terms of prolonged survival [11]. Our patient showed good response to the treatment: both AFP and PIVKA-II levels normalized, and mediastinal lymph nodes reduced in size.

Tumor stage, liver function, and the patient's general condition all affect the choice of the combination of treatments for a patient to receive. Although our patient was diagnosed with metastatic HCC, he has survived for more than 2 years, which significantly exceeds advancedstage HCC life expectancy.

\section{Statement of Ethics}

Informed consent was obtained from the patient.

\section{Disclosure Statement}

The authors have no conflicts of interest to declare.

\section{Funding Sources}

Medical Science and Technology Project of Zhejiang Province (2014KYA082), the Fundamental Research Funds for the Central Universities (2018FZA7002), and the Shulan Talent Foundation.

\section{Author Contributions}

Z.Y. was the doctor in charge of the patient and revised the manuscript, B.A. wrote the manuscript and analyzed the data, S.W. was the assistant doctor, Q.-F.X. was responsible for resources, S.-S.Z. proposed the study. S.-S.Z. is the guarantor. 
Yang et al:: Multidisciplinary Treatment of Advanced Hepatocellular Carcinoma

\section{References}

1 Bray F, Ferlay J, Soerjomataram I, Siegel RL, Torre LA, Jemal A. Global cancer statistics 2018: GLOBOCAN estimates of incidence and mortality worldwide for 36 cancers in 185 countries. CA Cancer J Clin. 2018 Nov;68(6):394-424.

2 Chen W, Zheng R, Baade PD, Zhang S, Zeng H, Bray F, et al. Cancer statistics in China, 2015. CA Cancer J Clin. 2016 Mar-Apr;66(2):115-32.

3 Massarweh NN, El-Serag HB. Epidemiology of Hepatocellular Carcinoma and Intrahepatic Cholangiocarcinoma. Cancer Contr. 2017 Jul-Sep;24(3):1073274817729245.

4 European Association For The Study Of The LiverEuropean Organisation For Research And Treatment Of Cancer. EASL-EORTC clinical practice guidelines: management of hepatocellular carcinoma. J Hepatol. 2012 Apr;56(4):908-43.

5 Forner A, Reig M, Bruix J. Hepatocellular carcinoma. Lancet. 2018 Mar;391(10127):1301-14.

6 Ronot M, Cauchy F, Gregoli B, Breguet R, Allaham W, Paradis V, et al. Sequential transarterial chemoembolization and portal vein embolization before resection is a valid oncological strategy for unilobar hepatocellular carcinoma regardless of the tumor burden. HPB (Oxford). 2016 Aug;18(8):684-90.

7 Qi X, Liu L, Wang D, Li H, Su C, Guo X. Hepatic resection alone versus in combination with pre- and postoperative transarterial chemoembolization for the treatment of hepatocellular carcinoma: a systematic review and meta-analysis. Oncotarget. 2015 Nov;6(34):36838-59.

8 Wei W, Jian PE, Li SH, Guo ZX, Zhang YF, Ling YH, et al. Adjuvant transcatheter arterial chemoembolization after curative resection for hepatocellular carcinoma patients with solitary tumor and microvascular invasion: a randomized clinical trial of efficacy and safety. Cancer Commun (Lond). 2018 Oct;38(1):61.

9 Parikh ND, Marshall VD, Singal AG, Nathan H, Lok AS, Balkrishnan R, et al. Survival and cost-effectiveness of sorafenib therapy in advanced hepatocellular carcinoma: an analysis of the SEER-Medicare database. Hepatology. 2017 Jan;65(1):122-33.

10 Li Q, Hu Y, Xi M, He L, Zhao L, Liu M. Sorafenib modulates the radio sensitivity of hepatocellular carcinoma cells in vitro in a schedule-dependent manner. BMC Cancer. 2012 Oct;12(1):485.

11 Wada Y, Takami Y, Matsushima H, Tateishi M, Ryu T, Yoshitomi M, et al. The Safety and Efficacy of Combination Therapy of Sorafenib and Radiotherapy for Advanced Hepatocellular Carcinoma: A Retrospective Study. Intern Med. 2018 May;57(10):1345-53.
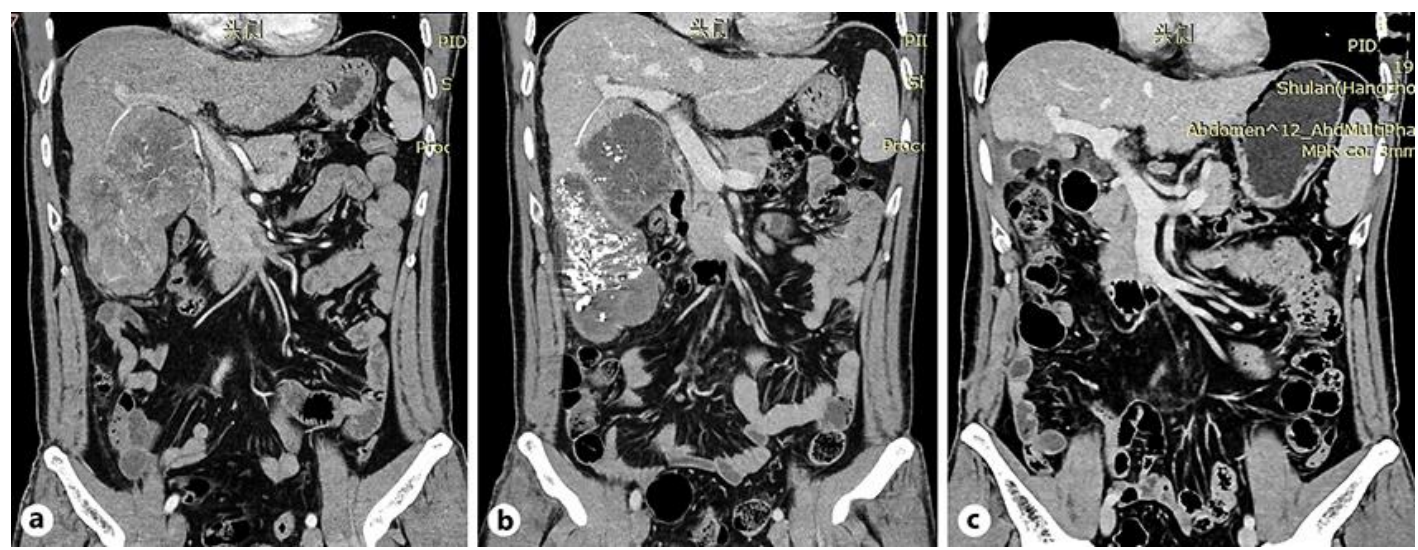

Fig. 1. Coronal CT scan of the abdomen on admission (a), after TAE (b), and after hepatectomy (c). 


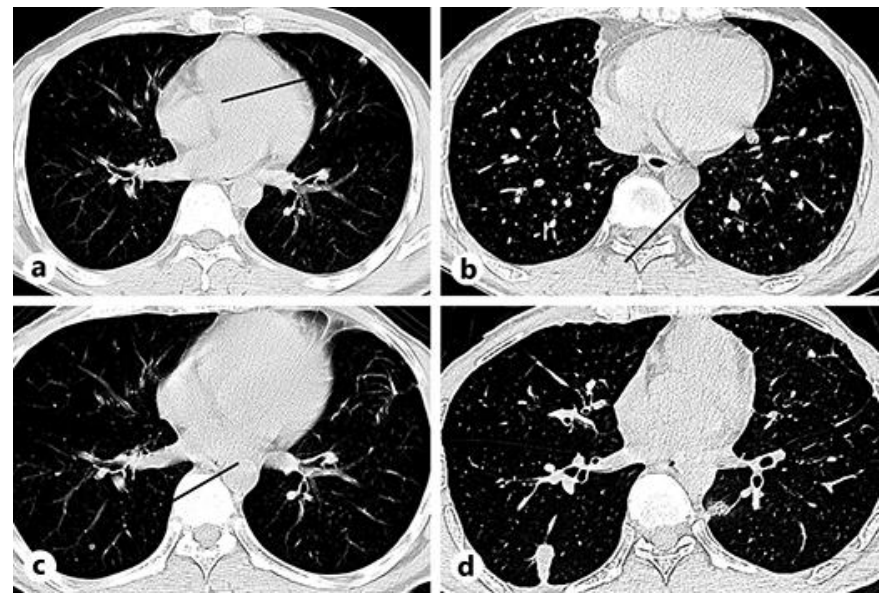

Fig. 2. Chest CT demonstrating a nodule in the superior lingular segment of the left upper lobe (a), a nodule near the left oblique fissure (b), a nodule in the right lower lobe before RFA (c), and an ablation zone after RFA (d).
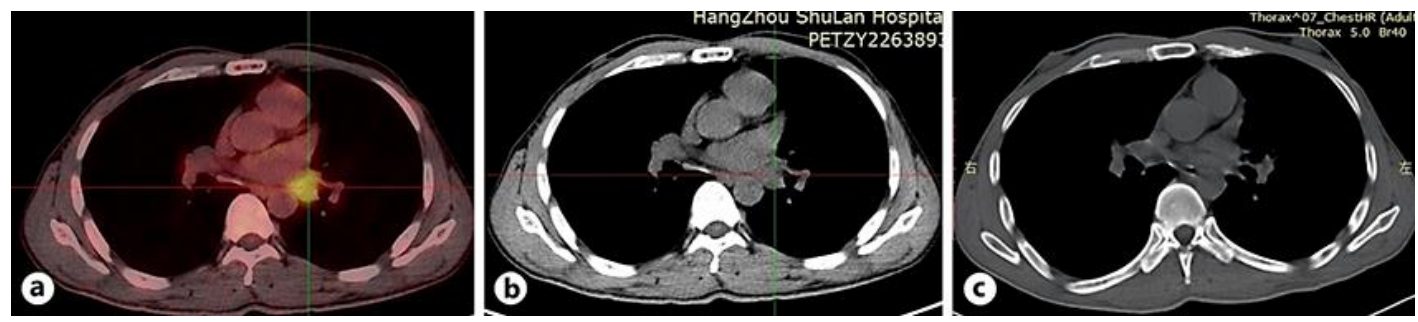

Fig. 3. a, b ${ }^{18}$ F FDG-PET/CT shows increased uptake in the left hilar lymph region. $\mathbf{c}$ Chest CT scan after radiotherapy.
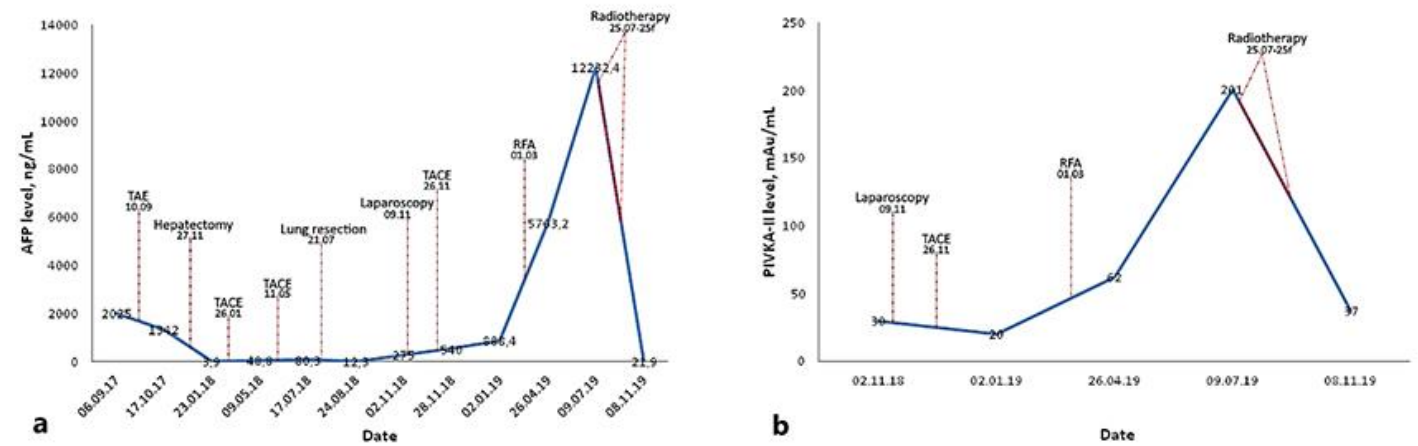

Fig. 4. Changes of AFP level (a) and PIVKA-II level (b) since admission. 